\title{
Failure of meperidine wound infiltration to reduce pain after laparoscopic tubal ligation
}

\begin{abstract}
Many women experience considerable pain and delay in return to regular activity afier laparoscopic iubal ligation. We performed a prospective randomized double-blind study to evaluate pain and recovery after laparopscopic tubal ligation and the influence of meperidine wound infiltration. After approval by the Ethics Committee, informed consent was obtained from 60 patients. All patients received naproxen $500 \mathrm{mg}$ po one hour before surgery. Patients were randomized into three groups. All patients received a standard general anaesthetic. Group $C$ patients $(n=18)$ received normal saline (NS) in the deltoid and $N S$ in the wound. Group $S$ patients $(n=21)$ received $50 \mathrm{mg}$ of meperidine in the deltoid and NS in the wound. Group $W$ patients $(n=21)$ received $50 \mathrm{mg}$ meperidine in the wound and NS in the deltoid. Afier surgery, pain and nausea were treated with morphine and metoclopramide as needed. Following hospital discharge, patients were contacted by telephone daily until they returned to regular activities. The mean maximum pain score of Group $S$ patients was lower than that of Group $C$ patients $(P<0.05)$. Group $S$ patients required less morphine in the Postanaesthesia Care Unit than the Group $C$ patients $(P<0.05)$. One Group $C$ patient was readmitted to hospital due to inadequate analgesia with oral medications. Group $S$ patients returned to regular activity earlier than the Group $C$ patients $(P<0.05)$. It is concluded that wound infiltration with meperidine did not affect pastoperative pain or recovery. Intramuscular administration of the same amount of
\end{abstract}

\section{Key words \\ ANAESTHESIA: outpatient; \\ ANALGESICS: meperidine; \\ PAIN: postoperative; \\ SURGERY: gynaecological.}

From the Department of Anaesthesia, University of Manitoba, Winnipeg, Manitoba, Canada.

Address corrrespondence to: Dr. B.Y. Ong, Department of Anesthesia, University of Manitoba, LB 315, 60 Pearl Street, Winnipeg, Manitoba, R3E 1X2.

Accepted for publication 2lst July, 1995. meperidine resulted in less pastoperative pain and earlier return to regular activity.

Après une ligature tubaire par laparascopie, les femmes ont souvent des douleurs considérable et leur retour à leurs activités habituelles est souvent retardé. Nous avons réalisé une étude prospective à double aveugle dans le but d'évaluer l'importance de la douleur et la rapidité de récupération après une ligature tubaire par laparascopie et linfluence de linfiltration de la plaie avec de la mépéridine. Après approbation par le comité d'éthique, un consentement éclairé a été obtenu de 60 patientes. Toutes ont reçu du naproxen $500 \mathrm{mg}$ p.o. une heure avant la chirurgie. Les patientes ont été réparties au hasard entre trois groupes. Toutes ont reçu une anesthésie standardisée. Les patientes du groupe $C(n=18)$ on reçu du soluté physiologique (SP) dans le deltoïde et dans la plaie. Celles de groupe $S$ (n $=21$ ) ont reçu $50 \mathrm{mg}$ de mépéridine dans le deltoïde et du $S P$ dans la plaie. Celles du groupe $W(n=21)$ ont reçu 50 $m g$ de mépéridine dans la plaie et du SP dans le deltoïde. Après la chirurgie, les douleurs et les nausées ont été traitées avec de la morphine et de la métoclopramide au besoin. Après leur départ de lhôpital, les patientes ont été appelées au téléphone quotidiennement jusqu'à leur retour à des activités normales. Le score maximum de douleur moyen des patients du groupe $S$ a été inférieur à celui des patientes du groupe $C(P<0,05)$. A la salle de réveil, les patientes du groupe $S$ ont eu besoin de moins de morphine que celles du groupe $C(P<0,05)$. Une patiente du groupe $C$ a dû être réadmise à lhôpital à cause de l'analgésie inadéquate produite par la médication orale. Les patientes du groupe $S$ ont repris leurs activités habituelles plus rapidement que celles du groupe $C$ $(P<0,05)$. Les auteurs concluent que linfiltration de la plaie avec de la mépéridine n'affectait pas la douleur et la récupération postopératoire. L'administration intramusculaire de la même quantité de mépéridine a diminué la douleur postopératoire et procuré un retour plus rapide aux activités habituelles.

Many women experience severe pain after laparoscopic tubal ligation. ${ }^{1-3}$ About $60 \%$ of these women require 
treatment with parenteral opioids. Preoperative treatment with non-steroidal anti-inflammatory agents (NSAID) can reduce pain after laparoscopic tubal ligation. ${ }^{2-4}$ However, many patients still experience severe pain and require parenteral opioid treatment. After hospital discharge, pain is associated with delayed return to normal activity. ${ }^{1}$

Meperidine has been used to produce surgical anaesthesia after intrathecal administration. Meperidine administration around peripheral nerves is associated with reduction in the amplitude of compound nerve action potentials. ${ }^{5}$ These observations suggest that meperidine has the potential to produce postoperative analgesia by its local anaesthetic effect locally and its narcotic effect systemically.

We performed a prospective, randomized, double-blind study to evaluate meperidine wound infiltration on postoperative pain and recovery in laparoscopic tubal ligation patients pretreated with the NSAID, naproxen. We also followed-up our patients after surgery to assess their postoperative morbidities and return to regular activities.

\section{Methods}

This study was approved by the University of Manitoba Committee on the Use of Human Subjects in Research. Written informed consents were obtained from 60 ASA physical class I or II patients scheduled for elective laparoscopic tubal ligation. Exclusion criteria were: additional procedures, weight $>100 \mathrm{~kg}$., difficulty with communication in English, not available for postoperative telephone contact, allergy to any of the study medications, and other contraindications to naproxen.

All patients received naproxen $500 \mathrm{mg}$ po one hour before surgery. Patients were randomized into three groups: Group C - Control, Group S - Shoulder, and Group W - Wound.

All patients received a standard anaesthetic induction with d-tubocurarine $0.04-0.05 \mathrm{mg} \cdot \mathrm{kg}^{-1}$, droperidol 10 $\mu \mathrm{g} \cdot \mathrm{kg}^{-1}$, thiopentone $4-6 \mathrm{mg} \cdot \mathrm{kg}^{-1}$, succinylcholine 1.5 $\mathrm{mg} \cdot \mathrm{kg}^{-1}$, and fentanyl $1 \mu \mathrm{g} \cdot \mathrm{kg}^{-1}$. After intubation, anaesthesia was maintained with $60 \%$ nitrous oxide, $40 \%$ oxygen, and isoflurane $0.5-1.5 \%$ end-tidal. Muscle relaxants and reversal were given at the attending anaesthetist's discretion. Although surgical technique was not standardized, all surgeons used Hulka clips for laparoscopic tubal ligation.

At the end of surgery, all patients received two injections. The anaesthetists administered a $1 \mathrm{ml}$ injection into the deltoid muscle and the surgeons infiltrated the wound with $10 \mathrm{ml}$ of a previously prepared solution. Surgeons were told to infiltrate as they would normally with local anaesthetic.

An assistant, not involved in caring for the patient, prepared the solutions based on instructions in sealed envelopes. Each envelope contained one of three instructions and each envelope was selected at random after all the envelopes were thoroughly mixed. Patients in Group C received normal saline (NS) in both injection sites. Group $S$ patients received $50 \mathrm{mg}$ of meperidine (1 $\mathrm{ml}$ ) in the deltoid muscle and $10 \mathrm{ml} \mathrm{NS}$ in the wound. The wounds of Group W patients were infiltrated with $50 \mathrm{mg}$ meperidine diluted in $9 \mathrm{ml}$ NS (total volume 10 $\mathrm{ml}$ ) and the intramuscular injection was $1 \mathrm{ml}$ of NS. The attending staff, nurses, the clinical investigator, and patients were all blinded to the identity of the solutions administered until all the patients had completed the study.

In the post-anaesthsia care unit (PACU), all patients were assessed by the same clinical investigator prior to the administration of any medication (analgesic or antiemetic). Predetermined assessment times were on admission and at $\mathbf{3 0} \mathrm{min}$ intervals for up to two hours. In addition, patients were assessed at intermediate times if the patient voiced any complaint or appeared uncomfortable. The severity of pain was assessed using a 100 $\mathrm{mm}$, horizontal, visual analogue scale (VAS). The trigger for analgesic administration was a VAS score greater than 25. Morphine was ordered in doses of $1.0-2.5 \mathrm{mg} i v$ based on the VAS and clinical assessment by the investigator. The same investigator managed all the assessments and ordered the analgesics and antiemetics. Morphine administration was continued until pain control was established. At each assessment, patients were asked whether or not they felt nauseated. Metoclopramide $i v$ was given to treat nausea if needed. The final assessment for all patients occurred when the patients were deemed ready for discharge from hospital as per established criteria. At our hospital, patients who undergo laparoscopic tubal ligation stay in the PACCU after surgery until discharge home.

Following discharge from hospital, patients were telephoned by the same clinical investigator and asked a standard set of questions. Patients were asked to rate their pain as none, minimal, little, some, lots, or maximum. All patients who said their pain was some, lots or maximum were considered to have severe pain. The patients were contacted every $24 \mathrm{hr}$ until they returned to regular activities. We defined full return to regular activity as being able to eat, move around, care for family, and able to go back to work (either outside the home or housework). The average number of days that the patients cannot resume their regular activity was calculated.

After all the patients completed the study, the treatments for the patients were identified and the data were grouped according to the treatments received. The demographic data of the three groups were analyzed for statistical significance using ANOVA. Pain (VAS) assess- 
TABLE I Demographic data

\begin{tabular}{lccc}
\hline & Group C & Group S & Group W \\
\hline Number & 18 & 21 & 21 \\
Age (yr) & $32 \pm 5$ & $33 \pm 4$ & $32 \pm 5$ \\
Height (cm) & $162 \pm 7$ & $160 \pm 5$ & $161 \pm 6$ \\
Weight (kg) & $68 \pm 10$ & $64 \pm 9$ & $60 \pm 10$ \\
Duration of anaesthesia (min) & $36 \pm 8$ & $38 \pm 8$ & $39 \pm 9$ \\
Gravidity & $3 \pm 2$ & $3 \pm 2$ & $3 \pm 1$ \\
Parity & $2 \pm 1$ & $2 \pm 1$ & $2 \pm 1$ \\
\hline
\end{tabular}

TABLE II Pain severity at predetermined assessment times in PACU

\begin{tabular}{llll}
\hline & Group $C$ & Group $S$ & Group $W$ \\
\hline 0 & $38 \pm 30$ & $13 \pm 13$ & $25 \pm 20$ \\
30 & $41 \pm 23$ & $26 \pm 16$ & $40 \pm 23$ \\
60 & $40 \pm 27$ & $24 \pm 14$ & $34 \pm 15$ \\
90 & $26 \pm 16$ & $19 \pm 9$ & $29 \pm 15$ \\
120 & $20 \pm 12$ & $19 \pm 7$ & $26 \pm 12$ \\
Discharge & $16 \pm 12$ & $11 \pm 8$ & $16 \pm 7$ \\
\hline
\end{tabular}

ments and other nonparametric data were compared using the Kruskal-Wallis test. After Kruskal-Wallis test, nonparametric comparisons of the control with the other groups were performed. ${ }^{6} \mathrm{~A}$ contingency table of patients in each group who had returned to regular activity on each day after surgery was constructed. Contingency tables were analyzed with Fisher's Exact Test if one or more of the expected values was $<5$. Other contingency tables were analyzed with chi-square analysis and Yates correction for small numbers. The calculations were performed using the Number Cruncher Statistical System. A $P$ value $<0.05$ was considered statistically significant. The results are presented as mean $\pm \mathrm{SD}$.

\section{Results}

Of the 60 patients in the study, 18 were randomized to Group C (Control), and 21 were in each of Groups S (Shoulder) and W (Wound). There was no difference between the groups with respect to age, height, weight, duration of anaesthesia, gravidity and parity (Table I).

Pain assessments at admission to the recovery room, at 30, 60, 90, $120 \mathrm{~min}$ after admission to PACU and at discharge from hospital were similar (Table II). The maximum VAS score was lower for Group S patients than Group C patients (Table III). The total dose of morphine administered in PACU was lower and the number of interventions for analgesia during the first hour in PACU was lower in Group $\mathbf{S}$ patients than Group $\mathrm{C}$ patients (Table III). There was no difference in the average duration of stay in hospital (Table III).

One of the control patients (Group C) had to be readmitted to hospital for $24 \mathrm{hr}$ on Day 2 because of in-
TABLE III Pain severity and recovery after surgery

\begin{tabular}{lrcc}
\hline & Group C & Group S & Group W \\
\hline First VAS & $42 \pm 29$ & $24 \pm 24$ & $31 \pm 23$ \\
Maximum VAS & $57 \pm 29$ & $36 \pm 22^{*}$ & $50 \pm 21$ \\
Discharge VAS & $16 \pm 12$ & $11 \pm 8$ & $16 \pm 7$ \\
Number of interventions (1st & & & \\
$\quad$ Hour) & $3 \pm 2$ & $1 \pm 2^{*}$ & $2 \pm 1$ \\
Number of interventions (Total) & $4 \pm 3$ & $2 \pm 3$ & $3 \pm 2$ \\
Amount of morphine (mg) & $9 \pm 7$ & $4 \pm 6^{*}$ & $6 \pm 4$ \\
Time of discharge (min) & $138 \pm 38$ & $138 \pm 45$ & $132 \pm 30$ \\
\hline
\end{tabular}

$* P<0.05$. Group S vs Group C.

TABLE IV Percentage of patients in each group who cared for their family during the first four days after discharge from hospital

\begin{tabular}{llll}
\hline Day(s) afier discharge & Group $C$ & Group $S$ & Group W \\
\hline One & $28 \%$ & $67 \% *$ & $24 \%$ \\
Two & $56 \%$ & $76 \%$ & $67 \%$ \\
Three & $72 \%$ & $95 \%$ & $86 \%$ \\
Four & $83 \%$ & $95 \%$ & $95 \%$ \\
\hline
\end{tabular}

* $P<0.05$. Group $\mathrm{S}$ vs Group $\mathrm{C}$ and Group $\mathrm{S}$ vs Group W.

adequate analgesia using oral medication. One patient from Group $S$ was excluded from analysis of return to regular activity because her family prevented her from doing anything. One patient from Group $W$ was excluded from analysis after three days because she developed a flu-like illness on day 4 after hospital discharge. Patients in Group $S$ needed $2.5 \pm 0.8$ days to return to regular activity compared to $3.1 \pm 1.1$ days for Group $W$ and 4.1 \pm 1.3 days for Group $C$ patients.

On the first day after discharge from hospital, more patients from Group S were caring for members of their family compared with patients in the other groups (Table IV).

Group $S$ patients had fewer complaints of feeling tired, dizzy, sore throat, or other subjective discomforts on the first day after discharge (Table V). Similar percentages of patients in the three groups had considerable pain after surgery, use of analgesic and had nausea during the first three days after discharge from hospital.

Sixteen patients (Group C - 5, Group S - 6, Group $W-5$ ) had nausea in the recovery room. Three patients (two nauseated and one not nauseated) were amenorrheic for more than 30 days before surgery. Patients in day 25 to day 4 of the menstrual cycle did not have higher incidence of nausea than did patients in days $5-19$ or patients in days $20-24$.

\section{Discussion}

In this study, wound infiltration with meperidine did not . affect postoperative pain or recovery. However, Group 
TABLE V Percentage of patients with one or more subjective complaints (excluding pain or nausea) during the first four days after discharge from hospital

\begin{tabular}{llll}
\hline Day(s) after discharge & Group C & Group S & Group W \\
\hline One & $89 \%$ & $52 \%^{*}$ & $76 \%$ \\
Two & $44 \%$ & $43 \%$ & $57 \%$ \\
Three & $44 \%$ & $14 \%$ & $19 \%$ \\
Four & $28 \%$ & $5 \%$ & $14 \%$ \\
\hline
\end{tabular}

$* P<0.05$. Group $S$ vs Group C.

$S$ patients who received an injection of the same amount of meperidine into the deltoid muscle had less intense postoperative pain in the PACU and were able to return to regular activity at an earlier time than Group C patients.

Since one of the investigators followed the patients closely in the PACU and provided analgesia as soon as patients voiced discomfort, the VAS scores at predetermined intervals were similar (Table II). Although Group $S$ patients had a smaller mean maximum VAS score and required less parenteral opioid in the PACU, these patients reported a similar incidence of severe pain and analgesic use after discharge. Therefore, the Group S patients appeared to be the same as the other patients in their appreciation of pain. The lower maximum VAS scores amongst these patients in the immediate postoperative period were probably related to the intramuscular meperidine administration.

Infiltration of the wound with local anaesthetic at the end of intraabdominal surgery may not reduce postoperative pain. ${ }^{7}$ The systemic analgesic effect of intramuscular meperidine reduced the immediate postoperative pain of the Group S patients. Infiltration of the wound with meperidine did not provide the same degree of analgesia. Pain from other areas might have masked any local analgesic effect. The absorption of meperidine from the wound was probably less efficient than the absorption from the intramuscular injection. The difference in systemic absorption may account for the difference observed in the postoperative levels of pain between Group $S$ and Group W subjects. Infiltration with higher doses may provide better results.

Group S patients were more active on the first postoperative day and required less time to return to regular activity. Although Group S patients had a similar degree of postoperative pain as patients in the other groups, they had less discomfort (Table V). The data suggest that postoperative subjective discomfort might delay resumption of daily activity. Previously, Fraser et al. ${ }^{1}$ found that patients could not resume normal activity for an average of 4.5 days after tubal ligation (consistent with Group C). During the first three days after surgery, $63 \%$ of the control patients in our study and $83 \%$ of the patients followed by Fraser et al. ${ }^{1}$ were unable to resume their regular daily activities because of pain or other symptoms. Further study is required in this area. With almost all such procedures performed as day surgery, patients should be prepared for considerable morbidity after hospital discharge. By the third day after surgery we found that many women still had pain, nausea and other symptoms and many could not care for their family.

The incidence of nausea in the immediate postoperative period was $27 \%$ for the three groups. This is less than the $50-60 \%$ incidence reported in untreated patients in previous studies, ${ }^{8-10}$ but is consistent with patients treated with droperidol $10 \mu \mathrm{g} \cdot \mathrm{kg}^{-1}$ in the study by Pandit et al. ${ }^{8}$ Nausea was not found to be related to the menstrual cycle in our study. Previous studies ${ }^{9,10}$ showing that nausea was related to the phase of the menstrual cycle are inconsistent. Honkavaara et al. ${ }^{9}$ found that the incidence of nausea and vomiting was highest during the luteal phase (days 20-24) and lowest during the perimenstrual phase (days 25-6). The more recent study by Beattie et $a .^{10}$ found that menstruating patients had a higher incidence of nausea and vomiting. Although there were only 60 patients in our study, this is similar to the number of patients in the previous study by Honkavaara et al. ${ }^{9}$

In conclusion, meperidine wound infiltration did not reduce pain or affect recovery after laparoscopic tubal ligation. Addition of meperidine $50 \mathrm{mg} \mathrm{im}$ at the end of surgery decreased the maximal intensity of postoperative pain and was associated with less subjective postoperative discomfort and an earlier return to regular activity.

\section{Acknowledgement}

We thank Ms. Paulette Morrison, RT and the nurses at the Post-anaesthesia Care Unit, Women's Hospital for their assistance in the study. We thank Ms. Mary Marko for her assistance in the preparation of this manuscript.

\section{References}

1 Fraser RA, Hotz SB, Hurtig JB, Hodges $S N$, Moher $D$ The prevalence and impact of pain after day-care tubal ligation surgery. Pain 1989; 39: 189-201.

2 Crocker $S$, Paech $M$. Preoperative rectal indomethacin for analgesia after laparoscopic sterilisation. Anaesth Intensive Care 1992; 20: 337-40.

3 Rasenblum M, Weller RS, Conard PL, Falvey EA, Gross $J B$. Ibuprofen provides longer lasting analgesia than fentanyl after laparoscopic surgery. Anesth Analg 1991; 73: 255-9.

4 Comfort VK, Code WE, Rooney ME, Yip RW. Naproxen premedication reduces postoperative tubal ligation pain. Can J Anaesth 1992; 39: 349-52. 
5 Kaya K, Babacan A, Beyazova M, Bölükbasi N, Akçabay $M$, Karadenizli $Y$. Effects of perineural opioids on nerve conduction of $N$. suralis in man. Acta Neurol Scand 1992; 85: 337-9.

6 Zar JH. Biostatistical Analysis. Englewood Cliffs: Prentice-Hall Inc., 1974: 156-9.

7 Trotter TN, Hayes-Gregson P, Robinson S, Cole L, Coley $S$, Fell $D$. Wound infiltration of local anaesthetic after lower segment Caesarean section. Anaesthesia 1991; 46: 404-7.

8 Pandit SK, Kothary SP, Pandit UA, Randel G, Levy L. Dose-response study of droperidol and metoclopramide as antiemetics for outpatient anesthesia. Anesth Analg 1989; 68: 798-802.

9 Honkavaara P, Lehtinen A-M, Hovorka J, Korttila $K$. Nausea and vomiting after gynaecological laparoscopy depends upon the phase of the menstrual cycle. Can J Anaesth 1991; 38: 876-9.

10 Beattie WS, Lindblad T, Buckley DN, Forrest JB. Menstruation increases the risk of nausea and vomiting after laparopscopy. Anesthesiology 1993; 78: 272-6. 